\title{
AVALIAÇÃO DE COMPETÊNCIAS ORGANIZACIONAIS DE ÓRGÃO PÚBLICO FEDERAL: ÓTICA DE DIFERENTES ATORES
}

\author{
Evaluation of organizational competences of the federal public body: \\ view from different actors
}

Lana Montezano

E-mail: lanamontezano@gmail.com

Doutorado em Administração - Universidade de Brasília.

Endereço para contato: Campus Universitário Darcy Ribeiro, Prédio da FACE, Bloco BT sala 41/7 -

Asa Norte, Brasília/DF, Brasil - CEP: 70. 910-900.

https://orcid.org/0000-0001-5288-4299

luri Sivinski Petry

E-mail: psiiuri@gmail.com

Graduando em Psicologia - Universidade de Brasília.

Endereço para contato: Campus Universitário Darcy Ribeiro, Prédio da FACE, Bloco BT sala 41/7 -

Asa Norte, Brasília/DF, Brasil - CEP: 70. 910-900.

https://orcid.org/0000-0002-6912-252X

Leila Barbieri de Matos Frossad

E-mail: Ibfrossard@hotmail.com

Mestrado em Administração Pública - Universidade de Brasília.

Endereço para contato: Campus Universitário Darcy Ribeiro, Prédio da FACE, Bloco BT sala 41/7 -

Asa Norte, Brasília/DF, Brasil - CEP: 70. 910-900.

https://orcid.org/0000-0002-1446-1655

Antonio Isidro

E-mail: antonio.isidro.filho@gmail.com

Doutorado em Administração - Universidade de Brasília.

Endereço para contato: Campus Universitário Darcy Ribeiro, Prédio da FACE, Bloco BT sala 41/7 -

Asa Norte, Brasília/DF, Brasil - CEP: 70. 910-900.

https://orcid.org/0000-0003-1174-8586

Artigo recebido em 31 de janeiro de 2021. Aceito em 26 de Agosto de 2021. 


\section{RESUMO}

A avaliação de competências organizacionais contribui ao alto desempenho em organizações públicas, devido ao fato de proporcionar ações ao desenvolvimento das suas capacidades organizacionais, a partir de possíveis lacunas identificadas. Objetivou-se avaliar as competências organizacionais de organização pública federal sob a ótica dos servidores internos e externos ao órgão, bem como verificar a existência de variáveis que possam influenciar na percepção da competência organizacional. A pesquisa é teóricoempírica, descritiva, com recorte transversal e abordagem quantitativa, com aplicação de questionários eletrônicos com 143 servidores (mais de 60\% da população), sendo tanto de público interno que trabalham na organização pública federal, como de público externo que atuem em unidades de órgãos federais, das três esferas de poder, com contato direto com a organização estudada. Utilizou-se análise estatística descritiva e inferencial (teste de Kruskal-Wallis). Constatou-se alta concordância quanto à demonstração das competências essenciais, corroborando com o cumprindo seu papel institucional junto à sociedade. Já a competência básica teve menor média de percepção, indicando necessidade de ações ao seu desenvolvimento. Não foram identificadas diferenças significativas entre a percepção dos grupos por tipo de público, enquanto, a depender a competência, há diferenças significativas quanto à esfera de poder, cargo, tempo de experiência e função de gestão. Os resultados podem ser utilizados no diagnóstico de competências para subsidiar ações de melhoria, inclusive como indicador de priorização do uso de recursos, devido a limitações orçamentárias das organizações públicas, além de propiciar contribuições metodológicas que podem ser replicadas por outras organizações para avaliação das competências organizacionais.

Palavras-chave: Avaliação de competências, Competência organizacional, Gestão por competências, Setor Público.

\section{ABSTRACT}

The evaluation of organizational competences contributes to high performance in public organizations, due to the fact of providing actions for the development of their organizational capacities, based on possible identified gaps. The objective of the research was to evaluate the organizational competencies of a federal public organization from the perspective of public servants, internal and external to the agency, as well as to verify the existence of variables that may influence the perception of organizational competence. The research is theoreticalempirical, descriptive, with a cross-sectional approach and a quantitative approach, with the application of electronic questionnaires with 143 servers (more than $60 \%$ of the population), both from internal public working in the federal public organization, and from external public that act in units of federal agencies, from the three spheres of power, with direct contact with the studied organization. Descriptive and inferential statistical analysis (KruskalWallis test) was used. There was a high level of agreement regarding the demonstration of essential competences, corroborating the fulfillment of its institutional role with society. Basic competence had a lower average of perception, pointing to the need for actions to improve its development. No significant differences were identified between the groups' perception by type of audience, while, depending on competence, there are significant differences regarding the sphere of power, position, time of experience and management function. The results can be used in the diagnosis of competencies to support improvement actions, including as an indicator of prioritizing the use of resources, due to budgetary limitations of public organizations, in addition to providing methodological contributions that can be replicated by other organizations to assess organizational competencies.

Keywords: Competency evaluation, Organizational competence, Competency management, Public sector. 


\section{INTRODUÇÃO}

As competências são um fenômeno multinível que ocorrem no nível das organizações, equipe e indivíduos e que possuem premissas da interdependência entre estes níveis, além de serem demonstradas em um determinado contexto, ou seja, para uma finalidade específica (Montezano \& Isidro, 2020). De modo geral, pode-se dizer que as competências representam as capacidades que as organizações, equipes e indivíduos possuem para gerar entregas de resultados ao bom desempenho.

O estabelecimento e desenvolvimento de competências organizacionais permite a entrega de resultados além do esperado, agregando mais valor à instituição (Prahalad \& Hamel, 1990) e sustentabilidade organizacional (Kuzma et al., 2017). O alinhamento entre as competências de uma organização e sua estratégia organizacional é essencial para o sucesso da instituição (Bryson et al., 2007; Butler \& Ferlie, 2020; Cardoso \& Matos, 2010; Ghedine, 2015; Munck \& Gallieli, 2015; Prahalad \& Hamel, 1990), e deve ser precedido da definição de missão e objetivos, possibilitando assim uma integração vertical - entre os comportamentos individuais e o alcance da estratégica. Existe também a integração horizontal - conceitos propagados em modelos de gestão por competência (GC) como os da Bélgica e os dos Países Baixos - onde os processos de gestão de pessoas (GP) são realizados a partir das vantagens do modelo de GC (Beeck \& Hondeghem, 2010; Leisink, 2010). Nesse sentido, para que haja a integração vertical, o estabelecimento de competências organizacionais é parte fundamental (Fleury \& Fleury, 2004) do design estratégico e da definição de portfolios de competências nas organizações (Eden \& Ackermann, 2010), e assim subsidiar a definição de competências individuais alinhadas ao alcance da missão institucional (Butler \& Ferlie, 2020; Kuzma et al., 2017; Montezano, 2019).

Bryson et al. (2007) afirmam que a identificação e desenvolvimento de capacidades e de competências organizacionais é premissa fundamental para o sucesso das organizações públicas para permitir entrega de maior valor público, ou seja, realizar prestação de serviços com qualidade, eficiência, eficácia e efetividade. Em estudo para identificar fatores que contribuem para o alcance do alto desempenho em organizações públicas, Waal (2010) aponta que um deles é a excelência nas competências essenciais da organização pública, e complementa que se os governos focassem em aperfeiçoamento dos fatores que influenciam o alto desempenho, as organizações poderiam efetivamente agregar valor para sociedade.

Em função disso, foram desenvolvidos modelos de gestão por competências voltados para o contexto público que incluem a necessidade de definição das competências organizacionais na etapa de mapeamento das competências, além das etapas captação, desenvolvimento, acompanhamento e avaliação, e retribuição por competências (Brandão \& Bahry, 2005), inclusive contemplando avaliação da existência das competências 
organizacionais (Montezano, 2019). Observa-se nestes modelos de gestão por competências que a definição das organizacionais é premissa para a definição das competências individuais, e que o resultado do diagnóstico subsidia os demais subsistemas do modelo de gestão. uso da prática de avaliação de competências organizacionais contribui para apresentar os melhores desempenhos de acordo com sua missão e objetivos estratégicos, bem como elucidar lacunas de desempenho para aprimoramento (Cavalcante \& Renault, 2018).

A adoção da gestão por competências pelo governo brasileiro foi institucionalizada pela publicação de normativos para legitimar a utilização na administração pública. $O$ primeiro foi o Decreto $n^{\circ}$ 5.707/2006, em que instituiu a Política Nacional de Desenvolvimento de Pessoal (PNDP) e onde conceituou a gestão por competências, atribuindo relevância ao modelo. Posteriormente, foi revogado pelo Decreto $n^{\circ} 9.991 / 2019$, em que atribuiu como instrumento da PNDP o Plano de Desenvolvimento de Pessoal (PDP), entrega anual de cada órgão e entidade do SIPEC das necessidades de desenvolvimento de seus servidores, contemplando as seguintes responsabilidades: alinhamento das ações de desenvolvimento com a estratégia do órgão ou entidade; estabelecimento de objetivos e metas institucionais para nortear as ações de desenvolvimento; e atendimento das necessidades administrativas, operacionais, estratégicas e táticas, presentes ou futuras.

Estudos da literatura indicam a necessidade de investigações empíricas sobre mapeamento de competências organizacionais (Munck \& Galleli, 2015), inclusive específicos no contexto público (Silva \& Quintana, 2014), em função da carência de estudos sobre identificação e avaliação de competências organizacionais, conforme relatado em revisão de literatura sobre o tema por Silva e Siena (2015), bem como há recomendações de pesquisas para identificação de antecedentes da percepção de competência organizacional (Kim et al., 2016). Tem-se, ainda, a recomendação de investigações que avaliem quantitativamente a percepção sobre as competências organizacionais em contexto público visando subsidiar diagnóstico e definição de ações de melhorias na organização para desenvolvimento organizacional (Montezano et al., 2020). Ao analisar as publicações sobre avaliação de competências organizacionais, observa-se que, de modo geral, as mesmas são feitas, em sua maioria por meio de estudos qualitativos, e a partir da ótica de gestores da organização, como é o caso do estudo de Cavalcante e Renault (2018). Além disso, esta carência de estudos sobre mapeamento de competências organizacionais no contexto do setor público é corroborada por Montezano e Petry (2020) ao constatarem em uma pesquisa que fizeram com 17 organizações públicas, que apenas três haviam realizado identificação de competências organizacionais durante a implantação da gestão por competências.

Destarte, é estabelecido como objetivo de estudo avaliar as competências organizacionais de uma organização pública federal sob a ótica dos servidores internos (que trabalham na organização) e externos ao órgão (que são clientes diretos dos serviços prestados pela organização), bem como verificar a existência de variáveis que podem influenciar na 
percepção da competência organizacional. A escolha de analisar sob diferentes óticas, tanto de servidores internos quanto dos externos que demandam e recebem os serviços prestados pela organização estudada, está alinhada a recomendação de Ghedine (2015) quanto a avaliar competências sob perspectivas distintas.

Com isso, a avaliação de competências organizacionais sob a ótica de diferentes atores gera subsídios de informações na etapa de diagnóstico de competências que contribuem para proposição de ações ao aperfeiçoamento organizacional, tanto na perspectiva de possíveis ações de desenvolvimento de competências individuais, como de condições da organização para que possa efetivamente agregar valor às entregas e aos objetivos estratégicos.

\section{FUNDAMENTAÇÃO TEÓRICA}

O referencial está estruturado em duas partes. São apresentadas as definições de competências organizacionais na primeira parte $e$, na segunda, são relatadas as formas de avaliações de competências organizacionais.

\subsection{COMPETÊNCIAS ORGANIZACIONAIS}

Ghedine (2015) afirma que uma das limitações quanto à definição de competências organizacionais nas instituições é decorrente da complexidade conceitual do construto e das diferentes abordagens de classificações. Em seu estudo, a autora descreve competência organizacional como "um conjunto coordenado de recursos e capacidades" (Ghedine, 2015, p. 285), e Butler e Ferlie (2020) definem como a capacidade dinâmica das organizações. Munck e Galleli (2015) complementam esta definição especificando que se refere à mobilização de recursos, sejam eles humanos ou não, ao alcance de um objetivo final. Para a gestão pública, Bryson et al. (2007) definem competências organizacionais como o conjunto de recursos provenientes de habilidades, ações, tecnologias e processos que propiciam o bom desempenho organizacional alinhado aos objetivos estratégicos.

A composição da estratégia organizacional ocorre a partir da compreensão de como são manifestadas as competências organizacionais, as quais contribuem para obtenção do sucesso organizacional, quando devidamente articuladas (Arantes \& Menezes, 2018). Ubeda e Santos (2008) complementam que além de subsidiar a definição dos processos organizacionais e dos produtos ofertados, as competências organizacionais contribuem para a identificação das competências individuais necessárias ao desenvolvimento organizacional. E ainda, Butler e Ferlie (2020) apontam que, em organizações públicas, a identificação e análise das competências organizacionais também permitem que os atores atuem nas restrições das capacidades para transformá-las em possibilidades de aperfeiçoamento organizacional. 
Como referência seminal no estabelecimento de competências organizacionais, Prahalad e Hamel (1990), com base na visão baseada em recursos, estabelecem as características das competências organizacionais essenciais, as quais remetem a um aprendizado coletivo na organização. Elas auxiliam na coordenação de habilidades de produção e na integração múltiplos fluxos de tecnologia, agregando valor no trabalho e na entrega de valor da organização. Os autores também acrescentam como competências essenciais a comunicação, o envolvimento e o comprometimento da organização para consolidação do negócio. Além dessas características, as competências essenciais devem contribuir aos benefícios dos produtos ou serviços aos usuários finais; e é de difícil imitação, sendo personalizada para a organização. Enfim, integram recursos tangíveis e intangíveis em produtos e serviços.

Ampliando os horizontes da competência organizacional, Mills et al. (2002), além de descrever as competências essenciais como centrais na estratégia e peças-chave para a sobrevivência da organização, existem as competências de suporte, as quais impulsionam ou auxiliam um leque de outras atividades da organização.

Um novo horizonte de competência organizacional é sugerido por Ruas (2005), as competências organizacionais básicas. Esta categoria é voltada para as funções básicas de operacionalização de uma organização, sendo relacionadas a um aspecto de sobrevivência a médio prazo. $O$ autor também apresenta as categorias de competências organizacionais seletivas (de função diferenciadora, proporcionando espaço de liderança no mercado atuante) e essenciais (de função excepcional, contribuindo para uma posição de pioneirismo no mercado internacional).

Eden e Ackermann (2010) avançam o debate sobre as competências organizacionais ao proporem a diferenciação conceitual entre competências distintivas e competências essenciais ou centrais (core competences). Os autores caracterizam competências distintivas com base em quatro diretrizes de análise, considerando o conceito central de competência como um recurso estrategicamente útil, a saber: (i) é passível de ser estrategicamente gerenciada de forma inequívoca ou precisa; (ii) é uma capacidade de fazer algo; (iii) gera resultados diferenciados para o ambiente externo; (iv) explora ativos distintivos da organização. Dessa forma, uma competência distintiva pode ser observada como uma unidade de análise organizacional que causa resultados diferenciados no mercado.

Por outro lado, Eden e Ackermann (2010) mostram que a competência essencial ou central deve ser definida não como uma unidade de análise, mas como um padrão distintivo de competências que configura uma rede de relações interdependentes entre competências distintivas e os objetivos estratégicos da organização. Os autores reforçam a noção defendida por Prahalad e Hamel (1990) de que o elemento central ou essencial da competência é estabelecido pela análise de relações entre esta e os objetivos, bem como pela exploração de competências por meio da modificação ou adição de objetivos no portfólio estratégico 
da organização. Dessa forma, o aspecto essencial de uma competência organizacional se dá por meio de um processo cíclico de descoberta ou o refinamento de competências distintivas numa rede de relações entre estas e os objetivos do negócio.

Desta forma, pode-se perceber que as competências organizacionais podem ser classificadas em duas tipologias - as essenciais e as básicas conforme corroborado por Carbone et al. (2016), sendo os tipos adotados como referência para a pesquisa empírica. Carbone et al. (2016) afirmam que as competências essenciais têm a finalidade de distinguir as organizações por representaram a identidade da missão institucional e que permitem a geração de entregas para satisfação dos usuários e clientes da organização, contribuindo para a sua sustentabilidade. Já as competências organizacionais básicas são necessárias ao funcionamento da organização. Os autores afirmam que a definição das competências organizacionais fornece elementos para o estabelecimento das competências individuais.

\subsection{AVALIAÇÕES DE COMPETÊNCIAS ORGANIZACIONAIS}

O primeiro passo para avaliação parte da análise do contexto interno e externo da organização, de modo a permitir identificar quais são as competências organizacionais necessárias ao cumprimento da missão institucional (Montezano, 2019). Ghedine (2015) complementa que é necessário identificar as capacidades que sustentam as competências organizacionais, e que a análise das competências organizacionais deveria ser feita por diferentes perspectivas, tanto internas quanto externas à organização, de modo a obter uma visão mais ampla e representativa, e não gerar viés de foco somente sob uma ótica. A avaliação da competência organizacional permite a identificação de aspectos que precisam ser melhorados para orientar ações ao desenvolvimento organizacional (Chen \& Ma, 2018).

Existem quatro razões principais para avaliar as competências organizacionais de uma organização, evidenciadas por Mills et al. (2002), são elas: (i) permitir o equilíbrio entre o curto prazo com o longo prazo; (ii) focar nos recursos que ajudam o aprimoramento da organização, sendo mais do que apenas nos objetivos de onde se almeja chegar; (iii) aumentar o entendimento sobre os principais impulsionadores de desempenho; (iv) direcionar o desenvolvimento de recursos.

Para a sugestão de um modelo de avaliação de competências organizacionais, King et al. (2002) apresentam uma proposta. Primeiramente, é necessário identificar as competências organizacionais para, no segundo passo, avaliá-las. Na avaliação, é indicado a criação de um questionário a ser enviado para funcionários de alta e média gerências podendo ser para todo o corpo gerencial ou para uma amostra representativa. Como tópicos de análise de competências, os autores apresentam os seguintes cinco: vantagem competitiva, consenso na gerência intermediária, caráter tácito, robustez e fixação. Sobre o caráter tácito, 
explicam que é algo resistente à codificação e à divulgação - em outras palavras, de difícil replicabilidade. A robustez é a resiliência da competência em relação à mudança do ambiente, quanto mais robusta a competência, menos o seu valor depende de circunstâncias externas. A fixação diz respeito à mobilidade de uma competência, ou seja, de poder ser transferida a outra empresa, sendo seus critérios de avaliação referentes a, por exemplo, bancos de dados, equipamentos, programas de software, sistemas gerenciais, missão, cultura, valores, conhecimentos e habilidades de seus funcionários. A avaliação finaliza com uma matriz de dois planos: consenso na gerência intermediária e nível de vantagem competitiva, sendo que cada um dos planos tem a avaliação baixa e alta. Dessa forma, quatro podem ser as abordagens gerenciais, uma para cada combinação de avaliação de plano.

Uma outra vantagem de se avaliar a percepção da competência organizacional é o fato de que ela tem um papel relevante na relação entre suporte organizacional e comprometimento afetivo com a organização, uma vez que os indivíduos tendem a se comprometer mais quando percebem que a organização que atuam é competente, o que gera uma necessidade maior de contribuir com o seu desempenho (Kim et al., 2016). Neste caso, esses autores definem como percepção de competência organizacional como a percepção do indivíduo em relação à capacidade da organização de alcançar seus objetivos e metas.

Cardoso e Matos (2010) realizaram uma avaliação das competências organizacionais de instituições financeiras públicas por meio de entrevistas com gestores, considerando a ótica da Visão Baseada em Recursos, e reforçaram a necessidade de alinhamento com a estratégia organizacional. Além disso, eles indicaram que este tipo de avaliação permite a identificação do potencial da organização e dos indivíduos para promover melhorias do desempenho organizacional.

A partir do modelo de Mills et al. (2002), Takahashi e Fischer (2009) avaliaram as competências organizacionais de outra organização pública, a partir da identificação de competências essenciais, organizacionais, de suporte e distintivas. $O$ resultado da avaliação resultou, principalmente, na necessidade de aprimoramento das competências de suporte, tendo em vista que a consequência natural é que o melhor desempenho dessa categoria impulsiona as outras categorias. Além do aprimoramento, foi identificada também a necessidade de criação de mais uma competência de suporte.

Por sua vez, Cavalcante e Renault (2018) realizaram a avaliação de competências organizacionais da Coordenação de Gestão Tecnológica da Fundação Oswaldo Cruz (Fiocruz), a partir de abordagem qualitativa por meio de entrevistas semiestruturadas com 10 gestores, análise documental e observação direta informal. A partir dos resultados do estudo destes autores, é evidente que a avaliação pôde contribuir para um melhor reconhecimento de atuação da organização, demonstrando quais competências devem ser foco de aprimoramento ou desenvolvimento para melhorar o desempenho da organização. 
Os estudos referenciados de avaliação de competências organizacionais foram importantes na perspectiva em que evidenciaram a possibilidade de aprimoramento de entrega de trabalho e de valor da organização. Os aspectos metodológicos da avaliação de competências organizacionais dessa pesquisa são apresentados a seguir.

\section{METODOLOGIA}

Trata-se de uma pesquisa teórico-empírica descritiva de abordagem quantitativa, com recorte transversal, que foi realizada por meio de questionário eletrônico para coleta da percepção do público-alvo da pesquisa.

A organização estudada é da Administração Pública Federal e trata de orçamento público, buscando a excelência da gestão de recursos públicos federais. Esta organização é composta por 217 servidores públicos, sendo que, como 33 estavam em algum tipo de afastamento, foram considerados como público interno da pesquisa 184 profissionais, tendo em vista que são os profissionais que atuam na execução das competências organizacionais. Além disso, essa organização atua diretamente com outras organizações de órgãos federais que lidam com orçamento. Para a aplicação do questionário foram listadas 48 organizações vinculadas aos Poderes Legislativo, Judiciário, Executivo e Ministério Público, sendo que os representantes destas unidades foram considerados como público externo da pesquisa, uma vez que possui maior interação com a organização estudada por receberem os serviços prestados e produtos entregues por ela, sendo considerados público com maior potencial de conhecimento sobre as competências organizacionais.

A organização possui uma competência organizacional básica (associada aos macroprocessos de suporte), e três essenciais (associadas aos macroprocessos finalísticos), e um total de 42 capacidades vinculadas a estas competências, as quais foram identificadas e validadas por meio de análise documental, em especial do planejamento estratégico para alinhamento com a estratégia organizacional, conforme diretrizes da literatura (Cardoso \& Matos, 2010; Fleury \& Fleury, 2004; Prahalad \& Hamel, 1990), entrevistas com representantes das unidades, bem como com aprovação da lista final pela Alta Administração.

Para o alcance do objetivo proposto, o instrumento de pesquisa foi elaborado em Google Forms e teve a estrutura e conteúdo validado com quatro pesquisadores, sendo uma doutora, uma doutoranda, uma graduada em administração e um graduando em psicologia. Além disso, foi realizada validação de conteúdo e semântica com gestores das áreas de desenvolvimento institucional, gestão estratégica e gestão de pessoas. A versão validada do questionário foi estruturada da seguinte forma: (i) apresentação da pesquisa, contendo objetivo da pesquisa, aspectos de sigilo das informações e não identificação do respondente, contato dos pesquisadores responsáveis, além de indicação quanto à concordância em 
participar da pesquisa; (ii) avaliação das competências organizacionais, por meio da utilização de quatro itens com a descrição das competências organizacionais e de suas 42 capacidades vinculadas a serem mensurados em uma escala de concordância tipo likert de cinco pontos, além da possibilidade do entrevistado marcar que não possuía conhecimento sobre o item para realizar avaliação; (iii) itens para mensuração sobre os requisitos para as competências organizacionais com uso da mesma escala likert e questões abertas para indicar pontos positivos e negativos sobre as dimensões dos requisitos; (iv) nove questões de múltipla escolha para caracterização do perfil sócio profissional do respondente. Ressalta-se que o escopo deste artigo não contempla a apresentação de resultados dos requisitos das competências (item iii do questionário), ou seja, das condições necessárias à demonstração das competências organizacionais.

A divulgação da pesquisa ao público interno foi realizada por meio de publicação de link na intranet, envio de e-mail pela gestão de pessoas e pelo Gabinete do representante máximo da Alta Administração, banner nos elevadores do prédio da organização, e divulgação presencial passando em todas as salas para explicar a pesquisa e pedir a participação. Já em relação ao público externo, foi realizada seleção de amostragem intencional, pois a intenção era focar como público nos representantes das unidades de orçamento, tendo em vista serem os profissionais que recebem diretamente os serviços e produtos gerados pela organização estudada. Ao público externo foram encaminhados um e-mail solicitando a participação, tanto pela área de gestão estratégica quanto pelos pesquisadores. No caso deste público, foi adotada estratégia adicional de visitar as áreas de orçamento da Esplanada dos Ministérios para preenchimento da pesquisa na versão impressa do questionário, sendo que, nos casos em que se obteve a participação por este meio, as respostas foram digitadas no link pela equipe de pesquisadores para atualização da base de dados coletados.

Os dados foram coletados entre setembro e outubro de 2019, sendo a base exportada para o Excel e importada ao SPSS para tratamento e realização de estatísticas descritivas: frequência, média (M), desvio padrão (DP) e coeficiente de variação (CV). Além disso, também foram realizados testes dos pressupostos estatísticos, e devido à ausência de normalidade da distribuição dos dados, realizou-se teste não paramétrico de KruskalWallis para comparação da percepção das médias dos grupos (Field, 2009) com variáveis categóricas relativas ao perfil profissional do respondente, de modo a verificar possíveis variáveis que influenciam a percepção da demonstração das competências organizacionais, seja pelo tipo de público, tempo de experiência, cargo de gestão, entre outras coletadas no questionário

Foi obtida uma amostra de 110 participantes do público interno, correspondendo a $60 \%$ da população disponível, e 33 do público externo, representando $69 \%$ da população deste público. Com isso, a amostra totalizou 143 respondentes, a partir de amostragem não 
probabilística por conveniência, devido a participação voluntária. A Tabela 1 apresenta o perfil dos respondentes, com as frequências percentuais por tipo de público.

Tabela 1

Perfil da Amostra da Pesquisa, por Tipo de Público-Alvo (continua)

\begin{tabular}{|c|c|c|}
\hline Variável & Público interno & Público externo \\
\hline Sexo & $\begin{array}{l}\text { Feminino }-24,5 \% \\
\text { Masculino }-75,5 \%\end{array}$ & $\begin{array}{l}\text { Feminino - } 21,2 \% \\
\text { Masculino }-78,8 \%\end{array}$ \\
\hline Faixa etária & $\begin{array}{l}\text { Menor que } 29 \text { anos - } 2,7 \% \\
\text { Entre } 30 \text { a } 39 \text { anos - } 27,3 \% \\
\text { Entre } 40 \text { a } 49 \text { anos - } 36,4 \% \\
\text { Entre } 50 \text { a } 59 \text { anos }-26,4 \% \\
\text { Maior que } 60 \text { anos }-7,3 \%\end{array}$ & $\begin{array}{l}\text { Menor que } 29 \text { anos - } 0 \% \\
\text { Entre } 30 \text { a } 39 \text { anos - } 30,3 \% \\
\text { Entre } 40 \text { a } 49 \text { anos - } 30,3 \% \\
\text { Entre } 50 \text { a } 59 \text { anos - } 27,3 \% \\
\text { Maior que } 60 \text { anos - } 12,1 \%\end{array}$ \\
\hline Nível de escolaridade & $\begin{array}{l}\text { Ensino Médio - 5,5\% } \\
\text { Ensino Superior - 27,3\% } \\
\text { Especialização - 42,7\% } \\
\text { Mestrado - } 20,9 \% \\
\text { Doutorado - 3,6\% }\end{array}$ & $\begin{array}{l}\text { Ensino Médio - 0\% } \\
\text { Ensino Superior - 27,3\% } \\
\text { Especialização - 39,4\% } \\
\text { Mestrado - 30,3\% } \\
\text { Doutorado - 3,0\% }\end{array}$ \\
\hline Área de atuação & $\begin{array}{l}\text { Área finalística - } 64 \% \\
\text { Área meio - } 36 \%\end{array}$ & $\begin{array}{l}\text { Ministério Público - } 6 \% \\
\text { Poder Executivo - 70\% } \\
\text { Poder Judiciário - } 15 \% \\
\text { Poder Legislativo - } 9 \%\end{array}$ \\
\hline Atuação como gestor & $\begin{array}{l}\text { Gestor - } 25,5 \% \\
\text { Não gestor - } 74,5 \%\end{array}$ & $\begin{array}{l}\text { Gestor - } 75,8 \% \\
\text { Não gestor - } 24,2 \%\end{array}$ \\
\hline $\begin{array}{l}\text { Tempo de experiência no } \\
\text { serviço público }\end{array}$ & $\begin{array}{l}\text { Até } 4 \text { anos - } 10,0 \% \\
\text { De } 5 \text { a } 9 \text { anos - } 19,1 \% \\
\text { De } 10 \text { a } 14 \text { anos - } 16,4 \% \\
\text { De } 15 \text { a } 19 \text { anos - } 19,1 \% \\
\text { De } 20 \text { a } 24 \text { anos }-14,5 \% \\
\text { De } 25 \text { a } 29 \text { anos }-6,4 \% \\
\text { Mais de } 30 \text { anos }-14,5 \%\end{array}$ & $\begin{array}{l}\text { Até } 4 \text { anos - } 0 \% \\
\text { De } 5 \text { a } 9 \text { anos - } 15,2 \% \\
\text { De } 10 \text { a } 14 \text { anos - } 24,2 \% \\
\text { De } 15 \text { a } 19 \text { anos - } 15,2 \% \\
\text { De } 20 \text { a } 24 \text { anos }-12,1 \% \\
\text { De } 25 \text { a } 29 \text { anos - } 6,1 \% \\
\text { Mais de } 30 \text { anos }-27,3 \%\end{array}$ \\
\hline
\end{tabular}

\section{ANÁLISE DE RESULTADOS}

Incialmente, na Tabela 2 são apresentadas as estatísticas descritivas, por tipo de público, inclusive com o percentual de respondentes que marcaram não conhecer (NC) aquela competência. Ressalta-se que não são apresentadas as estatísticas descritivas das capacidades vinculadas a cada competência organizacional, de modo a manter o sigilo da organização estudada. No entanto, são descritos resultados gerais a respeito delas. 
Tabela 2

Percepção das Competências Organizacionais sob a Ótica do Público Interno e Externo

\begin{tabular}{|c|c|c|c|c|c|c|c|c|c|}
\hline 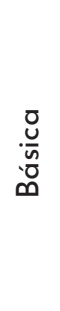 & $\begin{array}{l}\text { 1. Gestão de organização pública federal: Gerir } \\
\text { os recursos da organização para manutenção do } \\
\text { seu funcionamento e fornecimento de condições } \\
\text { para o alcance dos objetivos organizacionais, } \\
\text { com transparência e responsabilidade corpo- } \\
\text { rativa, e utilização de técnicas de qualidade e } \\
\text { inovação para melhoria contínua dos serviços } \\
\text { prestados à sociedade. }\end{array}$ & $8 \%$ & 3,66 & 1,1 & $30 \%$ & $12 \%$ & 4,14 & 0,9 & $22 \%$ \\
\hline 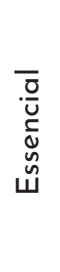 & $\begin{array}{l}\text { 2. Elaboração e normatização de orçamentos } \\
\text { federais: Elaborar leis e normas orçamentárias } \\
\text { federais, definindo normas disciplinadoras e } \\
\text { estrutura do gasto público, buscando sua correta } \\
\text { implementação e aperfeiçoamento do processo } \\
\text { orçamentário federal, com vistas a melhor apli- } \\
\text { cação dos recursos públicos. }\end{array}$ & $6 \%$ & 4,35 & 0,8 & $18 \%$ & O\% & 4,33 & 0,9 & $21 \%$ \\
\hline 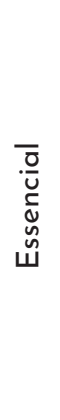 & $\begin{array}{l}\text { 3. Acompanhamento e avaliação da gestão } \\
\text { orçamentária e fiscal federal: Acompanhar e } \\
\text { avaliar a execução orçamentária e financeira } \\
\text { dos programas e aços do Governo Federal, bem } \\
\text { como projetar e acompanhar a arrecadação das } \\
\text { receitas federais, propiciando o uso de recursos } \\
\text { públicos federais de modo responsável, efetivo e } \\
\text { transparente, e em conformidade com os norma- } \\
\text { tivos estabelecidos pelo Governo Federal, além } \\
\text { de apreciação de proposições normativas com } \\
\text { potencial de impacto fiscal. }\end{array}$ & $5 \%$ & 4,26 & 0,7 & $17 \%$ & $0 \%$ & 4,42 & 0,9 & $20 \%$ \\
\hline $\begin{array}{l}\overline{\bar{\sigma}} \\
\overline{\check{L}} \\
\overline{\tilde{\nu}} \\
\tilde{\omega}\end{array}$ & $\begin{array}{l}\text { 4. Acompanhamento e avaliação de políticas } \\
\text { públicas com foco orçamentário: Realizar estu- } \\
\text { dos de políticas públicas com foco orçamentário } \\
\text { para melhor aproveitamento dos recursos públi- } \\
\text { cos existentes. }\end{array}$ & $10 \%$ & 3,69 & 1,1 & $30 \%$ & $6 \%$ & 4,13 & 1,2 & $30 \%$ \\
\hline
\end{tabular}

Em uma primeira análise, observa-se que tanto no público interno quanto no externo existem pessoas que não têm conhecimento de que a organização estudada possui aquela competência, sendo que o percentual de público interno com desconhecimento sobre as competências organizacionais essenciais é maior do que o público externo, o que poderia remeter a um indício de fragilidade. No entanto, este resultado deve ser analisado junto com a informação de que $36 \%$ dos respondentes trabalham na área meio e, dessa forma, de fato, podem desconhecer a competência. Em contrapartida, observa-se que $100 \%$ da amostra do público externo tem conhecimento das competências organizacionais 2 e 3, uma vez que recebem os resultados diretos destas competências. Já em relação à competência básica o desconhecimento é maior pelo público externo, o que faz sentido pelo fato de se tratar de capacidades relacionadas ao funcionamento da organização, e que os atores externos não possuem contato direto com as atividades relativas à gestão da organização pública em questão.

Em relação à competência organizacional "Gestão de organização pública federal", a média do público externo foi maior $(M=4,1)$ do que a do público interno $(M=3,7)$, no entanto 
não foi constatada diferença significativa entre elas $(p=0,335)$, com uso do teste de KruskalWallis. De modo geral, os dois públicos têm uma tendência a concordar que a organização demonstra esta competência, apesar de terem uma alta dispersão entre os respondentes, o que indica uma heterogeneidade na percepção dos participantes da pesquisa. Tem-se ainda que os servidores das áreas meio possuem maior média nesta competência organizacional do que os da área finalística, podendo ser justificado pelo fato de atuarem diretamente nos processos de trabalho relacionados à gestão da organização estudada. Assim como no estudo de Takahashi e Fischer (2009), esta pesquisa apresentou menores médias na competência básica, o que denota a necessidade do seu aperfeiçoamento, uma vez que este tipo de competência organizacional é subsídio para o funcionamento da organização, além de permitir a alavancagem das demais competências essenciais.

Também foram realizados outros testes de Kruskal-Wallis em relação a esta competência básica. Constatou-se que existe diferença significativa $(p=0,03)$ quanto à ocupação de cargo de gestor, sendo que gestores possuem maior percepção do que os não gestores, o que pode remeter ao fato de atuarem mais diretamente em atividades de gestão da própria organização. Não há diferença significativa $(p>0,05)$ entre os servidores das diferentes Esferas de Poder do público externo, quanto ao cargo que ocupam e quanto ao tempo de experiência no serviço público.

Na competência organizacional "Elaboração e normatização de orçamentos federais", pode-se perceber que as médias dos públicos interno e externo foram muito próximas, sendo de 4,4 e 4,3, respectivamente, e não possui diferença significativa $(p=0,066)$, apesar de que os servidores das áreas finalísticas possuem maior percepção do que os da área meio, o que é razoável, já que estes não trabalham com o tema. Observa-se um grau médio de dispersão no público interno e uma alta dispersão do público externo. Além disso, temse que, na avaliação das capacidades vinculadas a esta competência organizacional, os públicos interno e externo tiveram resultados similares do que percebem com maior ou menor demonstração delas, em função da proximidade de suas médias, sendo que todas foram superiores a 4. Com isso, tem-se boas médias na percepção dos servidores, podendo se inferir que para eles a organização estudada tem cumprido adequadamente o seu papel institucional, corroborando a definição de competências organizacionais alinhada ao objetivo organizacional, conforme Munck e Galleli (2015).

Nesta competência essencial de Elaboração e normatização de orçamentos federais, a partir do teste de Kruskal-Wallis, também não foram identificadas diferenças estatísticas significativas $(p>0,05)$ para os grupos quanto à ocupação de cargo de gestor e para as diferentes esferas de poder. No entanto, há significativa diferença $(p<0,05)$ quanto: (i) ao tempo de experiência, sendo que os aqueles estão entre 25 e 29 anos, bem como entre 5 e 9 anos possuem maiores percepção, enquanto os com mais de 30 anos possuem menor 
percepção, e (ii) ao cargo que ocupa, no qual os de nível superior possuem maior percepção daqueles de nível médio.

No que tange à competência organizacional "Acompanhamento e avaliação da gestão orçamentária e fiscal federal", também houve uma média próxima da percepção dos públicos interno $(M=4,3)$ e externo $(M=4,4)$, sendo que não há diferença estatística entre elas em uma significância de 0,089, além de ser a competência com menor dispersão nas respostas. Em complemento, apesar de não ter diferença entre os grupos, na média, os servidores das áreas meio possuem maior percepção quanto a esta competência organizacional daqueles de áreas finalísticas. Tem-se que todas as capacidades vinculadas obtiveram médias superiores a 4, sendo que, na maioria delas, a percepção do público externo é maior do que a do público interno. Com isso, também se pode inferir que a organização também tem atuado bem nesta competência organizacional essencial.

Com uso do mesmo teste não paramétrico de comparação entre grupos, aceita-se a hipótese de que as médias são similares $(p<0,05)$ quanto à ocupação de cargo de gestão, à esfera de poder e ao tempo de experiência. Já em relação ao cargo há diferença significativa $(p=0,002)$ e os de nível superior possuem maior percepção. Este resultado pode ser decorrente do fato destes cargos atuarem mais diretamente com as atividades finalísticas da organização para realização da prestação do serviço vinculada à sua missão institucional.

Por fim, a percepção dos públicos interno e externo acerca da competência organizacional "Acompanhamento e avaliação de políticas públicas" foi diferente, sendo melhor avaliado pelo externo com média de 4,13, enquanto que pelo interno foi de 3,69, e entre eles a percepção dos servidores da área meio foi maior do que da área finalística. Em relação às capacidades vinculadas a esta competência, todas obtiveram médias entre 3,25 e 3,68, indicando uma neutralidade dos participantes quanto à percepção delas. Da mesma forma, para os dois públicos as capacidades com melhores e piores avaliações foram as mesmas. $O$ resultado quanto a ser a menor média de percepção entre as competências essenciais para o público interno, além de ter a maior dispersão das respostas, pode ser decorrente do fato desta competência ser a mais recente atribuída a organização. $O$ resultado de não ter concordância maior que 4 na demonstração desta competência remete à possível necessidade de ações de desenvolvimento desta competência organizacional, inclusive possivelmente por meio de ações de desenvolvimento de competências individuais dos servidores que atuam nesta área, além de melhorias em práticas organizacionais e nos demais requisitos organizacionais condicionantes para a demonstração da referida competência essencial.

A partir do teste de Kruskal-Wallis, foi possível identificar que somente em relação ao tempo de experiência não há diferença significativa $(p=0,417)$ entre os grupos, enquanto que foram encontradas diferenças com significâncias menores que 0,05 em relação à: (i) 
ocupação de cargo de gestão, em que gestores têm maior percepção; (ii) esfera de poder, na qual a ordem de maiores percepções, de quem indicou ter conhecimento, foi na seguinte ordem - Ministério Público $(M=5)$; Judiciário $(M=4,8)$; Executivo $(M=4,0)$ e Legislativo $(M=2,5)$; (iii) cargo, sendo os de nível superior com maior percepção. Apesar dos servidores de nível médio terem apresentado menores médias que os demais cargos de nível superior que responderam à pesquisa em relação a competência "Acompanhamento e avaliação de políticas públicas", a média obtida dos cargos de nível médio pode ter viés pelo fato da maioria ter indicado que desconhece esta competência.

De um modo geral, o fato de as competências essenciais terem sido melhores percebidas pelos atores externos, pode remeter ao fato de ser resultado que são gerados pelas competências do que da competência organizacional em si, conforme argumentado por Eden e Ackermann (2010). Os resultados, de modo geral, também apontam a possibilidade de comprometimento dos servidores com a organização estudada, conforme achado de Kim et al. (2016), uma vez que possuem percepções, em média, superiores a 3,5, como indicativo de grau de concordância com a demonstração da competência, e os referidos autores indicam que quanto maior a percepção em relação à competência organizacional maior será o envolvimento dos profissionais.

Por fim, os resultados também permitem identificar potenciais de aprimoramento para o desenvolvimento organizacional, conforme foi realizado por Cardoso e Matos (2010) e por Cavalcante e Renault (2018), além de que este estudo avança com uso de abordagem quantitativa e com diferentes perspectivas.

\section{CONCLUSÕES}

O artigo apresentou a avaliação de competências organizacionais de um órgão público federal, sob a ótica dos servidores que trabalham nele (público interno) e os que recebem os serviços prestados mais diretamente pelo órgão (público externo), permitindo identificar que a organização vem cumprindo sua missão institucional devido às médias que indicam percepção de alta concordância dos dois públicos quanto à demonstração das competências essenciais de "2. Elaboração e normatização de orçamentos federais" e "Acompanhamento e avaliação da gestão orçamentária e fiscal federal", enquanto o resultado da avaliação da competência básica indica que existem pontos a serem aperfeiçoados para melhorar o bom funcionamento da organização. Além disso, não foram identificadas diferenças significativas entre a percepção dos grupos por tipo de público, enquanto, a depender a competência, há diferenças significativas quanto à esfera de poder, cargo, tempo de experiência e função de gestão. 
Os resultados podem ser utilizados no diagnóstico de competências para subsidiar ações de melhoria, conforme apontado por Butler e Ferlie (2020) e Chen e Ma (2018). Para tanto, pode-se partir de premissas como: onde há diferença de percepção entre grupos, fazse necessário promover melhorias na competência para o grupo que possui menor percepção; quando a percepção é inferior a quatro também pode ser indicativo da necessidade de aperfeiçoamento; os casos de alta dispersão indicam que existem pessoas com percepções bem abaixo da média e que demandam ações para fortalecer a demonstração da competência organizacional ou de sua capacidade.

Ainda sob a perspectiva prática, esta pesquisa também pode subsidiar informações na etapa de diagnóstico de competências do modelo de GC, e deve ser complementada com análises dos requisitos condicionantes às competências organizacionais, bem como às competências individuais para o estabelecimento de ações de desenvolvimento organizacional. Devido ao fato de as ações de desenvolvimento de competências precisarem ser feitas considerando o bom uso de recursos públicos, este resultado também pode servir como critério de priorização das competências organizacionais a serem desenvolvidas, e também das próprias competências individuais como mecanismo de aperfeiçoamento das organizacionais.

Do ponto de vista metodológico, o estudo contribui com a aplicação de uma abordagem quantitativa para mensuração de competências organizacionais, sob a ótica de público interno e externo, e de ter sido aberta a todos os servidores, sem restringir apenas a visão do gestor, além de contemplar profissionais da área meio e finalística do órgão estudado, de modo a permitir analisar com diferentes perspectivas. Além disso, também contribui com o avanço das pesquisas científicas ao identificar possíveis variáveis que influenciam a percepção das competências organizacionais, tais como cargo, tempo de experiência, ocupação de função de gestão, tipo de esfera de poder (no caso de público externo). Tem-se ainda que há diferença destas variáveis na influência do tipo de competência organizacional, ou seja, nas básicas ou essenciais.

Como limitações, tem-se o fato de ter sido utilizada amostra não probabilística por conveniência, não permitindo a generalização dos resultados. Além disso, a própria distribuição da amostra em alguns grupos de comparação não foi proporcional, como por exemplo, houve diferentes proporções entre as esferas de poder (público externo) e entre a área finalística e a meio (público interno), até mesmo da própria proporção da amostra entre o público interno e externo. Houve também dificuldades relativas à participação dos servidores, necessitando o reforço constante do convite em participar, além de casos de órgãos com dados de gestores desatualizados. Tem-se também o próprio aspecto contextual das competências essenciais que são específicas de uma organização, limitando a possibilidade de discussão de resultados com outros estudos. 
Como agenda de futuras pesquisas, recomenda-se realizar as seguintes investigações: (i) identificar e mensurar os requisitos para demonstração das competências organizacionais; (ii) testar a adequação da competência básica e de suas capacidades em outras organizações públicas, bem como comparar os resultados, além de identificar possíveis variáveis explicativas; (iii) identificar outras variáveis que possam influenciar a percepção das competências organizacionais; (iv) testar modelos de variáveis antecedentes e consequentes das competências organizacionais; ( $v$ ) testar empiricamente modelos multiníveis quanto ao alinhamento de competências organizacionais e individuais.

\section{REFERÊNCIAS}

Arantes, R. C. \& Menezes, R. S. S. (2018). Competências essenciais na produção de cafés especiais: um estudo de caso em uma fazenda no cerrado mineiro. XXI Seminários em Administração (SEMEAD), São Paulo, SP, 1-17.

Beeck, S. O., \& Hondeghem, A. (2010). Competency management in the Belgian Federal Government. K.U. Leuven, Public Management Institute.

Brandão, H. P., \& Bahry, C. P. (2005). Gestão por competências: métodos e técnicas para mapeamento de competências. Revista do Serviço Público, 2(56), 179-194.

Bryson, J. M., Ackermann, F., \& Eden, C. (2007). Putting the resource-based view of strategy and distinctive competencies to work in public organizations. Public Administration Review, 702-717.

Butler, M. J. R., \& Ferlie, E. (2020). Developing absortive capacity theory for public service organizations: Emerging UK Empirical Evidence. British Journal of Management, 31, $244-$ 364. https://doi.org/10.1111/1467-8551.12342.

Cardoso N. F., \& Matos, F. R. N. (2010). Competências organizacionais e gestão estratégica: um estudo em instituições financeiras públicas sob a ótica da visão baseada em recursos. Revista Eletrônica de ciência Administrativa (RECADM), 9(2), 168-180.

Cavalcante, F. V., \& Renault, T. B. (2018). Competências organizacionais do sistema de gestão tecnológica de uma instituição de ciência e tecnologia em saúde: o caso Fiocruz. XLII EnANPAD, Curitiba, PR, 1-17.

Chen, H., \& Ma, F. (2018). Development and validation of an organzational competency scale (OCS) for Elder civic engagement programs: a pilot study. Journal of Social Service Research, 1-14. https://doi.org/10.1080/01488376.2018.1514680.

Eden, C., \& Aackermann, F. (2010). Competences, distinctive competences, and core competences. In R. Sanchez, \& A. Heene (Eds.). Research in competence-based management: a focused issue on identifying, building, and linking competences (pp. 3-34). Bingley: Emerald. 
Field, A. (2009). Discovering statistics using SPSS. (3 ${ }^{a}$ ed.). London: Sage.

Fleury, M. T. L., \& Fleury, A. C. C. (2004). Alinhando estratégia e competências. Revista de Administração de Empresas, 44(1), 44-57.

Ghedine, T. (2015). Abordagem gestão por competências na construção da estratégia organizacional. Revista Alcance, 22(2), 278-297.

Kim, K. Y., Eeisenberger, R., \& Baik, K. (2016). Perceived organizational support and affective organizacional commitment: moderating influence of perceived organizational competence. Journal of Organizational Behavior, 37, 558-583.

King, A. W., Fowler, S. W., \& Zeithaml, C. P. (2002). Competências organizacionais e vantagem competitiva: o desafio da gerência intermediária. Revista de Administração de Empresas, 42(1), 36-49.

Leisink, P. (2010). Competency-based management in the national government of The Netherlands. K.U. Leuven, Public Management Institute.

Kuzma, E. L., Doliveira, S. L. D., \& Silva, A. Q. (2017). Competências para a sustentabilidade organizacional: uma revisão sistemática. Cadernos EBAPE.BR, 15, (Edição Especial), 428444.

Mills, J., Platts, K., Bourne, M., \& Richards, H. (2002). Competing through competences. Cambridge: Cambridge University Press.

Montezano, L. (2019). Proposta de modelo de gestão por competências para Administração pública. XLIII EnANPAD, São Paulo, SP, 1-15.

Montezano, L., França, J. V., \& Frossad, L. B. M. (2020). Definição de competências organizacionais em órgão da Administração Pública Federal. VII Encontro de Gestão de Pessoas e Relações de Trabalho da ANPAD, Online: EnGPR 2020, 1-10.

Montezano, L., \& Isidro, A. (2020). Proposta de modelo multinível de competências para gestão pública inovadora. Future Studies Research Journal: trends and strategies, 12(2), 355-378.

Montezano, L., \& Petry, I. S. (2020). Multicasos da implantação da gestão por competências na administração pública federal. Revista de Administração FACES Journal, 19(3), 47-66.

Munck, L., \& Galleli, B. (2015). Avanços e desafios da conceituação e operacionalização das competências organizacionais em 15 anos de produção científica internacional. Revista de Gestão, 22(4), 525-544.

Prahalad, C. K., \& Hamel, G. (1990). The Core Competence of the Corporation. Harvard Business Review, 1-15. 
Ruas, R. L. (2005). Gestão por competências: uma contribuição à estratégia das organizações. In R. L. Ruas, C. S. Antonello, \& L. H. Boff (Org.). Os novos horizontes da gestão: Aprendizagem organizacional e competências (pp. 34-54). Porto Alegre: Bookman.

Silva, M. R., \& Quintana, R. C. (2014). Aproximação do conceito de competência organizacional e gestão de organizações públicas. XXXVIII EnANPAD, Rio de Janeiro, 1-16.

Silva, R. S., \& Siena, O. (2015). Produção científica brasileira sobre competências organizacionais: estruturas, configurações e características do campo. XXXIX EnANPAD, Belo Horizonte, MG, 1-20.

Takahashi, A. R. W., \& Fischer, A. L. (2009). Aprendizagem e competências organizacionais em instituições de educação tecnológica: estudos de casos. Revista de Administração (RAUSP), 44(4), 327-341.

Ubeda, C. L., \& Santos, F. C. A. (2008). Os principais desafios da gestão de competências humanas em um Instituto público de pesquisa, Gestão \& Produção, 15(1), 189-199.

Waal, A. A. (2010). Achieving high performance in the public sector. Public Performance \& Management Review, 34(1), 81-103. 
